\title{
A QUESTÃO DO VÍRUS DA IMUNODEFICIÊNCIA HUMANA E A AUTOPROTEÇÃO NO TRABALHO
}

\author{
Alcione Bastos Rodrigues ${ }^{1}$ \\ Myrian Biaso Bacha Magalhăes ${ }^{2}$ \\ Stella Maris Monteiro Sales ${ }^{3}$
}

\begin{abstract}
RESUMO: O trabalho é um estudo descritivo exploratório com o objetivo de verificar a existência de normas e utilizaçăo de medidas de biossegurança pelo pessoal de enfermagem, na prevençăo da transmissăo do HIV durante a execução de procedimentos em unidades de internação de clínicas médico-cirúrgicas, em dois hospitais de Belo Horizonte. Através da observaçăo destes procedimentos, detectou-se a existência de riscos decorrentes do manuseio inadequado de secreções, excreções, roupas e campos contaminados, bem como a manipulação do material pérfurocortante, lixo e dejetos resultantes da execução dos procedimentos. Pode-se afirmar que os profissionais de enfermagem nas diversas categorias, conhecem as medidas de biossegurança, entretanto não as empregam adequadamente. A situação observada é preocupante e merece ser olhada com rigor pelas chefias de enfermagem dos estabelecimentos de saúde, visando maior controle da veiculação do HIV e busca de condições seguras de trabalho para os profissionais de enfermagem. Esta área necessita de investigação mais profunda visto serem percebidas condutas de risco na visão das pesquisadoras.
\end{abstract}

UNITERMOS: HIV/Biossegurança - Risco Ocupacional - HIV/Prática de Enfermagem.

\section{INTRODUÇÃO}

Existem diversos questionamentos sobre o exercício da profissão pelo enfermeiro e pelas diversas categorias que compőem a Enfermagem no Brasil.

A estrutura dos hospitais brasileiros prioriza a divisão do trabalho por categorias; a Enfermagem é uma das que tem marcado muito nitidamente a divisão do trabalho na área assistencial através da execução de tarefas desempenhadas por pessoal não qualificado. Segundo ALMEIDA ${ }^{1}$, as instituições de saúde vêm inserindo pessoas despreparadas no mercado de trabalho, delegando-Ihes tarefas para as quais não se exige conhecimento teórico e sim produção, pois o importante é a execução do tra- balho com economia de tempo e movimentos.

Essa situação se confronta com a que hoje os enfermeiros vivenciam, de questionamentos do seu papel como líderes da equipe de Enfermagem. OGUISSO ${ }^{22}$, analisando os papéis do enfermeiro e a questão da ampliação de suas funções, cita que a legislação em vigor em 1984, sobre o exercício profissional, atribuía ao enfermeiro, em caráter especifico, apenas as atividades administrativas e de ensino. As atividades componentes do exercício dessa profissão foram distribuídas igualmente a toda a equipe de Enfermagem, sem delimitação alguma entre as categorias que a compõem.

Essa situação permanece ainda hoje, mesmo com a aprovação da Lei n $7498 / 86$, que re-

Enfermeira - Professora auxiliar do Departamento de Enfermagem Básica da Escola de Enfermagem da UFMG. Enfermeira - Professora Assistente do Departamento de Enfermagem Básica da Escola de Enfemagem da UFMG. Enfermeira da Central de Material Esterilizado do Hospital das Clínicas da UFMG.

Enfermeira Maria Rizoneide N. de Araújo. Mestra em Enfermagem. Professora da Escola de Enfermagem da UFMG. Orientadora do trabalho. 
gula o exercício profissional, apesar do empenho das entidades de classe em regulamentar a formaçăo profissional.

O exercício da Enfermagem exige do profissional atitudes de enfrentamento diante da diversidade e gravidade das doenças que hoje acometem as pessoas. Dentre as doenças que constituem desafio para a Enfermagem, a AIDS assume relevância pela alta morbidade e mortalidade. $\mathrm{Na}$ área hospitalar, o enfermeiro depara-se com barreiras institucionais, pessoais, econômicas e técnicas para a implementaçăo de medidas de biossegurança, essenciais ao atendimento à saúde e à proteçăo dos profissionais da área.

PRAÇA e GRANDI ${ }^{24}$ enfocam que é relevante os riscos a que estão sujeitas as populaçőes que atuam na área hospitalar, devido ao contato com sangue e fluidos corpóreos dos pacientes nela tratados. Os autores citam que a Secretaria de Saúde de Săo Paulo considera pontencialmente infectados os indivíduos atendidos em ambulatórios, emergências, necrotério e na anatomia patológica, recomendando a utilizaçăo das medidas de biossegurança.

BERGAMO 4 recomenda que as cirurgias de emergéncia devem ser encaradas de forma especial no que diz respeito à transmissão do HIV e contaminação dos profissionais de saúde. Enfoca a necessidade de diminuir a transmissăo do vírus da AIDS por contato direto do paciente com o profissional através da determinaçăo de técnicas específicas, assepsia rigorosa e orientaçăo da aplicação dos procedimentos técnicos.

Algumas publicações do Ministério da Saú$\mathrm{de}^{17,20}$ abordam áreas de risco diferentes e outras reforçam a necessidade de se atuar preventivamente para controlar a AIDS, enfocando que pode ocorrer um maior risco de contrair HIV por transmissão parenteral, no Terceiro Mundo. Esse risco, segundo eles, deve-se à falta de treinamento do pessoal que administra medicamentos, à precariedade do equipamento disponivel e às práticas inadequadas de esterilização.

A transmissão do HIV atualmente não pode ser minimizada. O conhecimento das vias e formas de transmissão do vírus e seus mutantes pelo enfermeiro deve ser priorizado no emprego das medidas de biossegurança universais, para o desenvolvimento de suas atividades.

As medidas de precauçăo e biossegurança e o controle do número de casos săo formas de se efetuar a vigiláncia epidemiológica no sentido de evitar-se endemias.

MARIN e colaboradores ${ }^{15}$ reforçam a importância de as pessoas se conscientizarem da necessidade de mudança, na prática, das medidas de controle de infecção, em face da relevância dos portadores assintomáticos de HIV e de outros agentes patogénicos ainda não muito explorados.

As publicaçס̃es referentes à transmissão do vírus em profissionais da área de saúde são controvertidas e algumas: Jornal dos ConseIhos ${ }^{13}$; KLEIN ${ }^{14}$; Ministério da Saúde 17,20; PRAÇA e GRANDI ${ }^{24}$; MARIN ${ }^{15}$ consideram extremamente baixos os riscos de infecção pelo vírus, principalmente se as condições básicas de controle de infecção estiverem estabelecidas.

Durante nossas atividades docentes assistenciais nas unidades de internação médico-cirúrgicas de diversos hospitais de Belo Horizonte, observamos a existéncia de pessoas desqualificadas desempenhando funções às vezes privativas do enfermeiro, em decorréncia do seu tempo de casa e por serem tidos como competentes para uma determinada tarefa.

A admissão de pacientes era uma dessas atividades, normalmente delegadas ao pessoal mais desqualificado, recebendo uma supervisão indireta do enfermeiro, em muitos locais por nós utilizados para o ensino. Nestes, os funcionários de Enfermagem se limitavam a executar as prescriçőes médicas e de enfermagem sem tomarem conhecimento do diagnóstico do paciente, com risco de se contaminarem e disseminarem doenças, quando as pessoas eram portadoras de infecção.

Alguns profissionais envolvidos na prestação do cuidado ao paciente encaram, até com certo descaso, a utilização de medidas de biossegurança, indispensáveis com o advento da AIDS.

Em relação aos riscos ocupacionais, é difícil estabelecer os parâmetros de contaminação biológica pela não-utilização de medidas de pro- 
teçăo individual e coletivas, em virtude da existência de diferentes fatores que interferem na contaminaçăo, tais como: resistência individual, patogenicidade do agente, processo de esterilizaçăo utilizado, desinfecçăo e tipo de hospital, dentre outros, como a utilizaçăo prioritária de materiais descartáveis.

Em se tratando de exposiçăo ao HIV, as medidas de biossegurança săo fundamentais para prevenir a contaminaçăo daqueles que estăo em contato direto com portadores do vírus ou doentes, independente dos fatores acima mencionados.

PRAÇA e GRANDI ${ }^{24}$, em investigaçăo junto ao pessoal que atende na área obstétrica, afirmam haver negligéncia quanto a aspectos preventivos e que isto pode contribuir para a disseminaçăo da AIDS. As autoras citadas, analisando o papel da enfermeira obstétrica como líder do pessoal de Enfermagem do centro obstétrico, citam que a sua liderança năo se faz sentir de maneira a contribuir para a diminuiçăo da ansiedade da equipe quanto à contaminaçăo pelo HIV, quer supervisionando-a, quer formulando rotinas para o atendimento da clientela, visando uniformizar condutas de enfermagem diante do risco da doença.

O Ministério da Saúde ${ }^{17}$ e o Código da Ética Médica ${ }^{10}$ enfocam a questăo do sigilo do profissional médico no que diz respeito ao diagnóstico de AIDS, reforçando a manutençăo deste quando o paciente năo autoriza o profissional a divulgar esse diagnóstico. Entretanto esse codigo garante o conhecimento pelos outros profissionais do diagnóstico do cliente, também em caráter sigiloso, para prestar assistência com segurança, evitando submeter os trabalhadores de Enfermagem a fontes maiores de risco, por năo utilizarem as medidas de biossegurança universais. Várias vezes observou-se que o diagnóstico inicial é outro, secundário à AIDS, como, por exemplo, as patologias que acometem o aparelho respiratório e o sistema autoimune, sendo.o diagnóstico definitivo estabelecido posteriormente quando já ocorreram vários contatos do cliente com a equipe de Enfermagem sem que fossem tomadas as devidas precauçర̃es.
A situaçăo é tăo séria que o Ministério da Saúde ${ }^{19}$ afirma que a AIDS tem colocado em discussăo posiçőeś éticas do profissional de saúde até entăo tidas como indubitáveis, como, por exemplo, a questăo do segredo médico, ante a saúde de terceiros e a coletividade.

Portanto, considera-se relevante conhecer o que ocorre na prestaçăo de cuidados aos pacientes pelo pessoal de Enfermagem, em relaçăo à utilizaçăo de medidas de biossegurança em unidades de internaçăo.

\section{OBJETIVO}

Verificar a existência de normas e utilizaçăo de medidas de biossegurança pelo pessoal de enfermagem, na prevençăo da transmissăo do HIV durante execuçăo de procedimentos em unidades de internaçăo de clínicas médico-cirúrgicas, em dois hospitais de Belo Horizonte.

\section{METODOLOGIA}

Foi desenvolvido um estudo exploratório, descritivo, em dois hospitais gerais da cidade de Belo Horizonte.

Um dos hospitais selecionados pertence à rede pública de saúde e o outro pertence à rede privada, ambos atendendo a clientes adultos, sem distinçăo de sexo, nas clínicas médica e cirúrgica.

A escolha dessas instituiçס̆es para o estudo proposto deveu-se a:

- serem campo de estágio de alunos do curso de graduação em enfermagem, das disciplinas ministradas pelas pesquisadoras;

- năo serem hospitais específicos para o tratamento de AIDS;

- admitirem pacientes decorrentes de um atendimento de emergência;

- possuírem recursos humanos, materiais e equipamentos que permitam a aplicação das medidas de biossegurança no desempenho das atividades de enfermagem. 


\subsection{População}

A populaçăo a ser estudada foi constituída por unidades de internaçăo de Clínica Médica e Cirúrgica e os respectivos procedimentos de enfermagem nela executados.

Foi utilizada uma metodologia quantitativa, na tentativa de conhecer a situação vigente, na área de enfermagem quanto à existência e à utilização das medidas de biossegurança.

Para o presente estudo, foram consideradas Normas de Biossegurança aquelas preconizadas pelo Ministério da Saúde ${ }^{21}$, que visam tornar mais seguro o relacionamento dos profissionais de saúde entre si e com os pacientes. São relativas ao paciente, ao profissional de saúde, ao local e equipamento e à manipulaçăo do material biológico.

Visando à operacionalização das normas propostas, a Secretaria Nacional de Programas Especiais de Saúde do Ministério da Saúde faz recomendaçőes aos enfermeiros de como aplicar as medidas de biossegurança no seu exercício profissional, sendo o presente trabalho subsidiado por essas medidas.

Para o estudo proposto, as autoras definiram como medidas de biossegurança $o$ conjunto de medidas empregadas pelo indivíduo, no seu processo de trabalho, que permite a sua autoproteção e a manutenção de sua condição de saúde, ao mesmo tempo que estabelece condições seguras e protetoras para o paciente.

\subsection{Amostra}

Constou de procedimentos realizados rotineiramente nas Unidades de Internação selecionadas para o estudo.

\section{COLETA DE DADOS}

Foi realizada pelas autoras, com a colaboração de duas alunas do $7^{\circ}$ período do curso de graduação em enfermagem da UFMG, nos meses de novembro e dezembro de 1993, nas instituições A e B.
Efetuou-se observaçăo direta dos procedimentos selecionados, executados pelos membros da equipe de Enfermagem, durante o processo de trabalho na Unidade de Internação.

As pesquisadoras optaram por coletar dados no turno matutino, visto ser este o período de maior concentraçăo de atividades.

A coleta iniciou-se após comunicaçăo escrita à chefia de enfermagem e apresentaçăo à enfermeira responsável pelo setor.

Relatado o objetivo do estudo, passou-se ao levantamento dos procedimentos a serem realizados no período da observaçăo de acordo com a listagem pré-elaborada. No momento da aplicação do instrumento, fez-se a apresentação do pesquisador ao funcionário, na qual esclareceuse tratar de uma observação de procedimentos, sem explicitar os objetivos propostos. Essa conduta foi adotada para evitar que o funcionário modificasse seu comportamento no que se referia à utilização de medidas de biossegurança, fato observado no pré-teste.

O instrumento utilizado constou de trés partes, sendo a primeira uma identificação da instituição e da existência na mesma de medidas de biossegurança sistematizadas. A segunda parte relaciona-se à observação do procedimento referente à utilização de medidas de biossegurança. A terceira parte refere-se a cuidados na utilização de determinados materiais hospitalares, manuseio de secreções e dejetos hospitalares.

\section{TRATAMENTO DOS DADOS}

Os dados foram apurados pelo processo manual e tratados estatisticamente através de percentuais (\%), bem como analisados qualitativa e quantitativamente.

\section{VALIDAÇÃO DO INSTRUMENTO}

A validação foi realizada em um hospital de grande porte, com características semelhantes às das duas instituiçőes escolhidas para realização da pesquisa, tais como:

- ser campo de estágio de alunos do curso de Enfermagem; 
- atender pacientes decorrentes de um atendimento de emergência;

- atender diversas clínicas médicas e cinúrgicas.

O instrumento foi aplicado na unidade de intemaçăo na medida em que ocorriam os procedimentos, sem seleçåo prévia, fazendo-se a observaçăo sem interferência do pesquisador, com a finalidade de verificar a viabilidade do mesmo quanto ao conteúdo, objetividade e clareza.

A validaçăo determinou a necessidade de algumas alteraçర̃es no instrumento, tais como a delimitaçăo de procedimentos que implicassem na utilizaçăo de medidas de biossegurança no seu desempenho, sem entretanto incorrerem nele mudanças estruturais.

Os procedimentos selecionados para observação foram:

- curativo;

- banho no leito;

- lavagem intestinal;

- retirada de pontos;

- aspiração de traqueostomia;

- manuseio de cateter heparinizado;

- administraçăo de dieta por sonda;

- soroterapia;

- administraçăo de medicaçăo por via subcutânea;

- administraçăo de medicaçăo por via intramuscular;

- administraçăo de medicaçăo por via endovenosa.

Não houve preocupação com o quantitativo, e sim com o qualitativo, garantindo a observaçăo de cada procedimento selecionado.

\section{ANÁLISE E APRESENTAÇÃO DOS DADOS}

A análise e apresentação dos dados foi separada em três partes, compativeis com o instrumento de coleta de dados supracitado.

\subsection{Dados Referentes à Instituição e Exis- tência de Material Descartável}

A existência de normas de biossegurança foi constatada nas duas instituiçőes. Essas normas, na instituiçăo $A$, constituíram-se de um manual e cartazes que orientavam sobre a lavagem das măos e a năo reencapagem de agulhas, bem como seu destino após o uso. O manual encontrava-se na sala da supervisăo de Enfermagem.

$\mathrm{Na}$ instituiçăo $\mathrm{B}$, existiam quatro folhetos afixados nos postos de enfermagem e em prontuários dos pacientes.

Estes folhetos possuiam características distintas entre si, identificados como procedimentos $1,2,3$ e 4, com ilustraçőes das medidas preconizadas na parte anterior; no verso, incluia orientaçס̋es sobre essas medidas indicadas, quais sejam: paramentaçăo, lavagem das mãos, utilizaçăo e descarte de material perfurocortante e tipo de acomodaçăo (quarto privativo ou nểo).

Um folheto possuia indicaçăo sobre a utilizaçăo de várias medidas de biossegurança e, dentre elas, o uso de máscaras; entretanto, no verso não havia explicaçóes da necessidade de seu uso. Tais folhetos ficavam afixados em um quadro do posto de enfermagem e em alguns prontuários, sendo visível apenas a gravura, ficando impedida a leitura das orientaçőes contidas no verso.

Segundo o Ministério da Saúde 20 , o uso de normas de biossegurança impöe-se tanto no aspecto de proteçăo do profissional de saúde quanto no controle da AIDS e na melhor assistência aos pacientes. Todo profissional de saúde deve conhecer as normas de biossegurança e empregá-las adequadamente.

Foram levantados alguns dados gerais sobre categoria funcional, sexo, tempo de serviço, escolaridade e turno de trabalho.

TABELA 1

\begin{tabular}{|c|c|c|c|c|}
\hline \multicolumn{5}{|c|}{$\begin{array}{l}\text { Categoria Funcional do Pessoal de Enformagem } \\
\text { Observado nas UTI das Instituiç6es A — B - BH - Dez/1993 }\end{array}$} \\
\hline \multirow{2}{*}{ Categoria } & \multicolumn{2}{|c|}{ A } & \multicolumn{2}{|c|}{ B } \\
\hline & $\mathbf{N}^{\circ}$ & $\%$ & $\mathbf{N}^{0}$ & $\%$ \\
\hline $\begin{array}{l}\text { Auxiliar de } \\
\text { Enfermagem }\end{array}$ & 7 & 87,5 & 5 & 50 \\
\hline $\begin{array}{l}\text { Técnico de } \\
\text { Enfermagem }\end{array}$ & 1 & 12,5 & $z$ & $z$ \\
\hline Atendente & $z$ & $z$ & 5 & 50 \\
\hline Total & 8 & 100 & 10 & 100 \\
\hline
\end{tabular}

- Z = Zero 
Os dados mostram, na instituiçăo $A$, uma predominância $(87,5 \%)$ da categoria auxiliar de enfermagem entre os funcionários que executaram os procedimentos observados, e na instituição $B$, uma equivalência entre as categorias auxiliar e atendente de enfermagem (50\%).

Dentre as categorias observadas năo ocorreu desempenho de procedimentos envolvendo o enfermeiro. Tal fato reforça a afirmaçăo de FERNANDES ${ }^{12}$ de que o que se tem observado, em realidade, é uma escassez de recursos humanos de todos os níveis. $E$, dessa escassez, nota-se a predomináncia de uma mão-deobra elementar năo qualificada e, portanto, mais barata, além de uma carência de profissionais de nivel superior.

MENDES ${ }^{16}$ afirma que o enfermeiro se afasta de sua função de responsável direto pela assistência de enfermagem ao paciente, família e comunidade, assumindo outras funçőes, como a administrativa, sofrendo influência de uma série de fatores extrínsecos ao seu campo de prática e dos quais ele năo detém controle, que distorcem ainda mais suas funçőes; a assistencial é freqüentemente delegada aos demais componentes da equipe de enfermagem inabilitados para as funçőes que executam, exercendo-as sem eficiência e eficácia.

Nas unidades de internaçőes observadas, existia um enfermeiro apenas para o exercício da supervisão de enfermagem.

Segundo MENDES ${ }^{16}$, o que se tem observado é uma inversão da prática, com predominância das funçőes administrativas, e outras, distanciando o enfermeiro da função assistencial, embora os instrumentos normativos delimitem legalmente o espaço assistencial, tentando, inclusive, evitar as possíveis invasőes ao campo da prática médica.

Quanto ao sexo dos funcionários de enfermagem na instituição $A, 87,5 \%$ eram pertencentes ao sexo feminino e $12,5 \%$ ao sexo masculino. $\mathrm{Na}$ instituição $\mathrm{B}, 70 \%$ dos funcionários pertenciam ao sexo feminino e $30 \%$ ao sexo masculino.

Os dados coletados quanto ao sexo reforçam as afirmaçőes de vários autores FERNANDES $^{12}$, MENDES $^{16}$, ALMEIDA $^{02}$, de que a en- fermagem é uma profissão predominantemente feminina, com raízes históricas quanto à prestação de cuidados aos doentes pelas mulheres, desde a Idade Média em que o cuidado era prestado no lar, associado às atividades domésticas.

O levantamento sobre a força de trabalho em enfermagem no Brasil, efetuado em 1985 pelo COFEN/ ABEN, relata haver uma tendéncia de crescimento da participação masculina nessa profissão, sendo que nas décadas de 70 a 80 houve aumento do contingente masculino com formação em nivel superior.

Comparando-se as duas instituiçőes, verifica-se que o contingente de funcionários masculinos da instituição $B$ representa mais que o dobro do percentual obtido na instituição $A$.

Os dados obtidos mostram que na instituição $A$ os funcionários possuem a escolaridade mínima exigida pelo CFE para a função exercida, visto a totalidade ter o primeiro ou segundo grau concluído. Coincidentemente essa instituição é pública, o que pressupõe que se exija a qualificação prevista em lei.

$\mathrm{Na}$ instituição $\mathrm{B}$, apenas $10 \%$ dos funcionários têm o segundo grau concluído e só $60 \%$, o primeiro grau completo. $30 \%$ dos funcionários não tem nem a escolaridade mínima exigida. Destacamos que esta é uma instituição privada. SILVA 26 afirma que os hospitais privados buscam racionalização de custos no âmbito do setor privado, regendo-se pela lógica da lucratividade; percebe-se que pouca importância se dá à titulação de determinadas categorias profissionais no setor privado, pois isso implicaria em maiores gastos, diminuindo a margem de lucro em face da exigência de salários compativeis e melhorias quanto à prestação da assisténcia.

ANGERAMI ${ }^{3}$ complementa esta posição com a afirmação de que quanto mais elevada a formação profissional, maior é a distância deste profissional do paciente, desenvolvendo funçőes denominadas administrativas. Os elementos de menor preparo profissional, ou seja atendentes e auxiliares, são os que realmente permanecem 24 horas ao lado do paciente.

Reverter essa situação deve ser compromisso dos enfermeiros, especialmente daqueles que 
atuam no âmbito hospitalar e no ensino. Os primeiros têm responsabilidades no sentido de permitir e veicular informaçőes técnicas no nivel de instruçăo de seus funcionários para a autoproteçăo no trabalho e no manuseio seguro de pacientes graves e de risco, inclusive aqueles com AIDS. Os que atuam na área de ensino têm responsabilidades no que diz respeito à formação de consciência critica dos novos profissionais, alertando-os para os perigos de sua omissão na utilização das medidas universais de biossegurança preconizadas.

A priorizaçăo do uso de material descartável ocorre nas duas instituiçőes observadas. Esse material se encontra ao alcance de todos, visto que $100 \%$ dos funcionários informaram essa ocorréncia. Entretanto, mediante as observaçőes da năo-utilizaçăo de medidas de biossegurança, parecem carecer de informaçర̋es acerca da pertinência e adequação das mesmas aos procedimentos executados.

O Ministério da Saúde 21 afirma que é responsabilidade dos profissionais prover cuidado adequado à grande demanda de doentes, adotando normas corretas de biossegurança, mas reconhece que a resposta a esse desafio năo tem sido a mais adequada.

DESSUNTI ${ }^{11}$ apud MENEGHIN (1986), reforça que há um grupo de profissionais de enfermagem atingido pela desinformaçăo, seja pela dificuldade de acesso à literatura atualizada, seja pelas atuais condiçőes de vida que exigem do profissional maior dedicação ao trabatho em detrimento da própria atualizaçăo e do aprimoramento cientifico.

O observado nas instituiçס̋es investigadas é que na maioria das vezes o funcionário tem duplicidade de emprego com conseqüente sobrecarga da jornada de trabalho. A instituição não lhe exige aquisiçăo de novos conteúdos e nem os proporciona através de treinamentos formais no horário de trabalho para que ele aprofunde seus conhecimentos visando à melhoria e segurança na assistência. Exigem produtividade para o atendimento da demanda, sem analisar riscos e qualidade da assistência prestada.

DESSUNTI ${ }^{11}$ cita OLIVEIRA (1986), MENEGHIN (1986), GUERRA (1985) e PRATT (1987), que reforçam a situação descrita anteriormente alegando que muitos problemas relativos à AIDS foram amenizados com a educaçăo continuada.

Outro fatoobservado que merece maior aprofundamento é o gasto indiscriminado de material descartável em face da desinformaçăo do funcionário, provavelmente onerando os estabelecimentos de saúde, desviando verbas que poderiam ser utilizadas em benefício do próprio paciente ou na educação continuada desses profissionais.

A minimizaçăo de grande parte dos problemas observados, na percepçăo das pesquisadoras, poderia ser feita através da melhoria da comunicação interprofissional, visto estar ocorrendo maior comunicaçăo escrita e visual que a verbal, esclarecedora de situaçőes de conflitos.

\subsection{Dados Referentes à Utilização das Medi- das de Biossegurança no Desempenho dos Procedimentos}

As medidas de biossegurança observadas nas duas instituiçőes foram:

1. lavagem das måos;

2. uso de luvas;

3 . uso de óculos;

4 . uso de máscara.

\subsubsection{Lavagem das Mãos}

A lavagem das mãos, segundo normas ministeriais, deve ser feita de paciente para paciente, a cada procedimento e, no mínimo, antes e após cada procedimento executado. É recomendável o uso de água e sabão.

$\mathrm{Na}$ instituição $\mathrm{A}$, antes da execução dos procedimentos, $25 \%$ dos funcionários lavaram as mãos com água e sabão, $37,5 \%$ utilizaram somente água e $37,5 \%$ não lavaram as mãos.

$\mathrm{Na}$ instituição $\mathrm{B}$, antes da execução dos procedimentos, apenas $10 \%$ lavaram com água e sabão; $10 \%$ utilizaram somente água e $80 \%$ não lavaram as mãos.

A situação encontrada pode ser considerada alarmante, visto ser a lavagem das mãos o 
procedimento mais elementar e indispensável ao lidar com diversas pessoas, quanto mais nos casos observados, que eram pacientes de clínicas cirúrgicas, com integridade cutâneo-mucosa interrompida temporariamente pelo ato cirúr- gico, estando sujeitos a infecçőes secundárias pela manipulação sem cuidados, visto a cobertura epitelial da ferida cirúrgica efetivar-se a partir de 48 horas, de acordo com o Manual de Infecçőes Hospitalares ${ }^{8}$.

\section{GRÁFICO 3}

OCORRÊNCIA DA LAVAGEM DAS MÃOS, ANTES DA EXECUÇÃO DO PROCEDIMENTO NAS U.I. DAS INSTITUIÇÕES A e B - BH - DEZ.I93.

INSTITUIÇÃO A

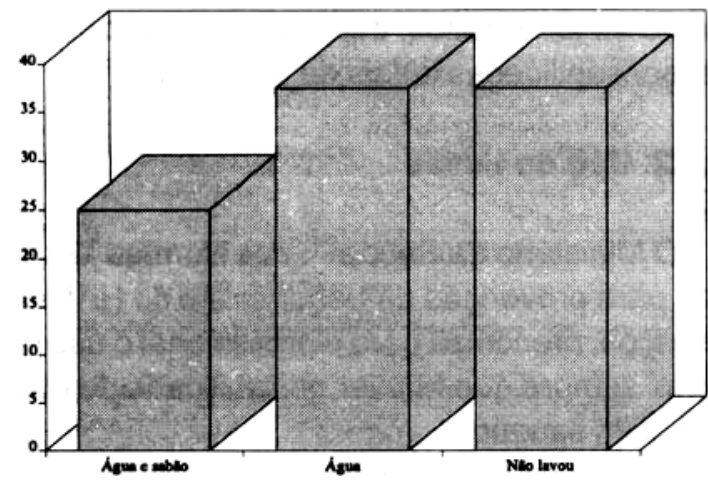

Após a execução dos procedimentos, a situação nas duas instituiçőes foi a seguinte :

Instituição A: 12,5\% dos funcionários lavaram as mãos com água e sabăo, $25 \%$ somente
INSTITUIÇÃO B

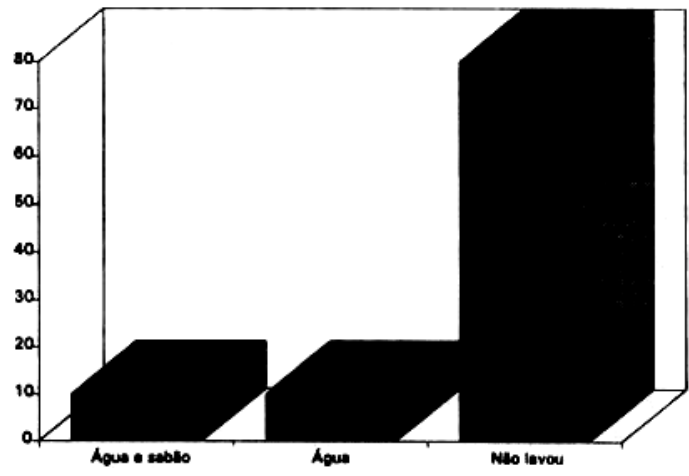

com água, $25 \%$ não lavaram e $37,5 \%$ utilizaram apenas antissepsia com álcool.

Instituição B: apenas $10 \%$ dos funcionários lavaram com água e sabão, $10 \%$ somente com água e $80 \%$ não lavaram as mãos.

\section{GRÁFICO 4}

\section{OCORRÊNCIA DA LAVAGEM DAS MÃOS, APÓS A EXECUÇÃO DO PROCEDIMENTO NAS}

\section{U.I. DAS INSTITUIÇÕES A e B -BH - DEZ./93.}

\section{INSTITUIÇÃO A}

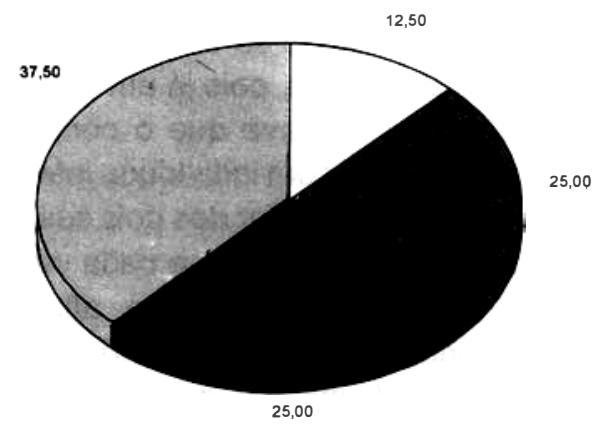

Água e sabão

Água

Não lavou

$\square$ Atissepsia com álcool

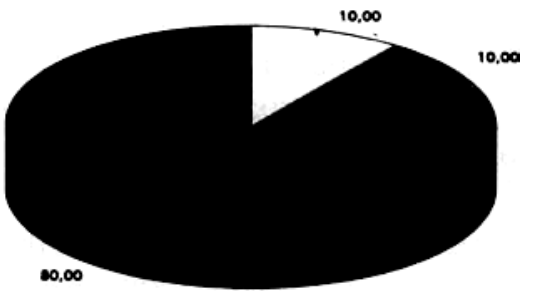


Analisando-se a utilizaçăo da lavagem das mãos, percebe-se, nas duas instituiçőes, que os percentuais estão abaixo do desejado, pois esta medida requeria $100 \%$ de utilizaçăo.

A Comissão de Infecção do Hospital das Clinicas da UFMG ${ }^{8}$ preconiza que deve-se "lavar as mãos antes e após a execuçăo de procedimentos."

O Ministério da Saúde 21 recomenda a lavagem das mãos com água e sabăo e secagem com papel-toalha branco ou compressa estéril, antes e após o atendimento de cada paciente.

Pode-se afirmar, mediante as situaçőes observadas, que as duas instituiçőes têm utilizado essa medida de biossegurança de forma inadequada, insegura para o desempenho das atividades de enfermagem, diante do surgimento da AIDS, quando a utilização das medidas de biossegurança săo imprescindíveis.

A lavagem das mãos com água e sabão é um procedimento eficaz no controle das infecçőes, tanto nas unidades de internação quanto nos locais de atendimento à saúde, pois apresenta a vantagem de ser um procedimento de mais baixo custo que o uso dos anti-sépticos preconizados, exigindo poucos recursos para ser viabilizado, já que a realidade encontrada é que todas as unidades dispunham de uma pia com sabão e papel-toalha.

Não se polemiza a questão do acesso aos mesmos, visto existirem situações opostas de fácil ou difícil acesso. O que se questiona é o fato de se omitir o passo "lavagem das mãos ao final do procedimento executado ", substituindo-o pela anti-sepsia com álcool, quando se sabe que a remoção mecânica da flora, através da água e sabão, é efetiva.

A omissão desse passo ocorreu com um percentual expressivo dos funcionários observados $(37,5 \%)$, aumentando o risco de o cliente cirúrgico adquirir infecção cruzada, pela negligência dos profissionais que dele cuidam.

OGUISSO 22 já alertava o pessoal de enfermagem quanto a sua responsabilidade legal, podendo ser incluídos no art. 135 do Código Penal brasileiro, pois este prevê que constitui crime de maus-tratos expor a perigo a vida ou a saú- de de pessoa sob sua autoridade, guarda ou vigilância, para fim de tratamento ou custódia. A autora reforça que năo é difícil ser envolvido em crime de homicídio culposo em pleno exercício da enfermagem, se não houver diligência, atenção e correta observância das regras técnicas da profissão. Finaliza afirmando que o pessoal médico e de enfermagem pode tranformar-se num veículo importante de transmissão de moléstias graves e que o uso de lavagem das mãos pode reduzir o risco de infecção. Enfatiza que os enfermeiros precisam estudar e acompanhar a evolução dos conhecimentos científicos, mantendo-se atualizados, especialmente quanto às responsabilidades legais da profissão.

\subsubsection{Uso de Luvas}

O Ministério da Saúde ${ }^{21}$, nas Normas Técnicas para prevençăo da transmissão do HIV nos serviços, preconiza para o profissional o uso de luvas sempre que houver possibilidade de contato com sangue.

Os tipos de luvas a serem usados são classificados, segundo o próprio Ministério da Saúde em relaçăo ao material e aos procedimentos a que se destinam, em:

- vinil - tipo ginecológico. Encontradas em tamanho único, não são elásticas, o que as tornam frágeis. São suficientes para a realização de um exame clínico;

- látex - luva cirúrgica. Usada para procedimentos clínicos e cirúrgicos;

- borracha - utilizadas para limpeza de instrumental e superfícies contaminadas, por serem mais grossas e mais resistentes.

O uso de luvas torna-se cada vez mais necessário nos dias atuais, pois já em 1989 o Ministério da Saúde alertava que o contato dos profissionais da área com indivíduos infectados pelo HIV, sem que qualquer dos dois saibam da existência da infecção, torna-se cada vez mais freqüente. Diante dessa realidade, afirma que este profissional deve considerar todo sangue $e$ secreção, excluindo lágrima, suor e saliva como potencialmente infectantes. 
Isso significa que estão indicadas rotineiramente precauçð̋es com sangue e secreçర̃es que năo săo específicas para o HIV.

Para MARIN ${ }^{15}$, esta crescente prevaléncia do HIV aumenta o risco dos profissionais, especialmente quando năo seguem as precauçőes necessárias.

A CCIH do Hospital das Clínicas da UFMG reforça que as luvas deverăo ser, de preferência, descartáveis e usadas para contato direto com material biológico ou artigos de superfícies contaminados pelo mesmo.

\section{GRÁFICO 5}

\section{OCORRÊNCIA DO USO DE LUVAS DURANTE A EXECUÇÃO DO PROCEDIMENTO NA U.I. DA INSTITUIÇÃO A - BH - DEZ./1993.}

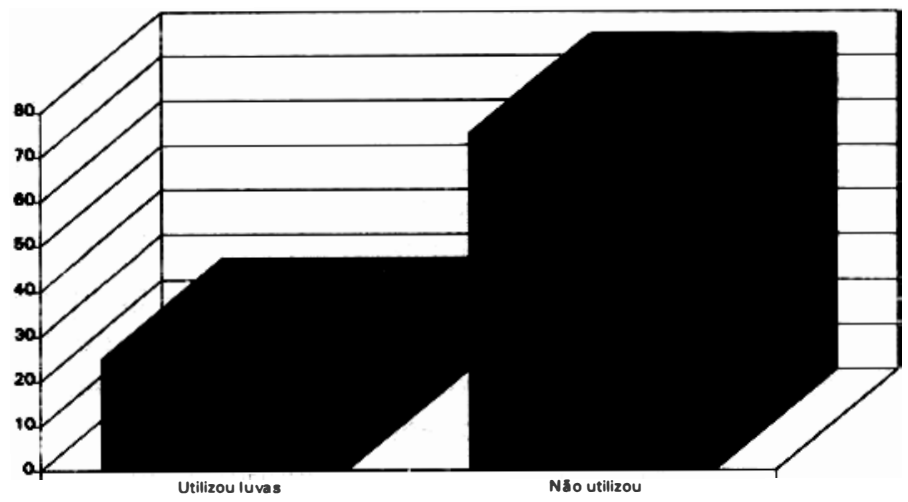

GRÁFICO 6

\section{OCORRÊNCIA DO USO DE LUVAS} DURANTE A EXECUÇÃO DO PROCEDIMENTO NAS U.I. DA INSTITUIÇÃO B - BH - DEZ./1993.

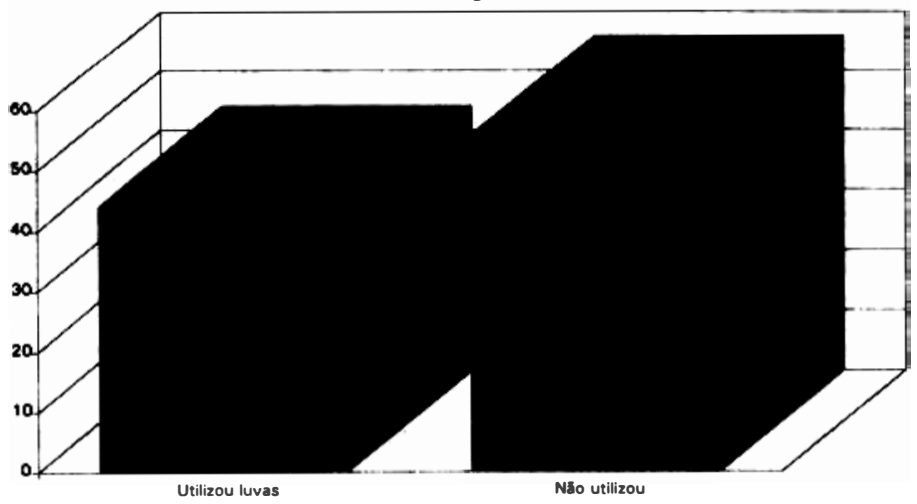

$\mathrm{Na}$ instituiçăo A, 25\% dos funcionários utilizaram luvas para banho de leito e curativo. Nestes procedimentos havia a possibilidade de contato com sangue e fluidos. Os funcionários justificaram a sua utilizaçăo alegando a exigência do procedimento e conduta pessoal.

Merece destacar que a utilizaçăo das luvas năo impediu a contaminaçăo dos funcionários durante os procedimentos, uma vez que em uma situaçăo observada houve contato direto da pele do funcionário com o sangue do paciente, sendo esta superficie limpa com algodăo, sem que se procedesse à lavagem da superficie atingida. Em outra situaçăo observada, houve contato do antebraço do funcionário com a urina do paciente, mas o local năo foi lavado após a contaminaçăo.

$\mathrm{Na}$ instituiçăo $\mathrm{B}, 44 \%$ dos funcionários utilizaram luvas para: aspiração de traqueostomia, banho de leito, curativo e lavagem intestinal. A utilizaçăo das mesmas foi justificada por eles como devida à possibilidade de contato com sangue e outros fluidos, conduta pessoal e exigência do procedimento.

Pressupōe-se que a utilização das luvas visava apenas à autoproteção, pois observou-se a utilização de um mesmo par de luvas na realização de vários curativos envolvendo manuseio de sangue, resultando em risco de contaminação do paciente, do ambiente e do pessoal.

Esses fatos são agravados pela conduta do funcionário não ter removido as luvas mesmo quando utilizou as instalaçŏes sanitárias.

Apesar de inferirmos que a utilização das luvas visava à autoproteção, questionamos se estas serviram mesmo para tal fim, uma vez que consideramos ser a autoproteção a utilização de medidas para evitar contaminação pessoal, o que é reforçado pelo $\mathrm{Ma}$ nual de Infecções Hospitalares da $\mathrm{CCIH}$ do HC da UFMG8: "para quem vai prestar serviços em contato 
permanente com doentes deverá ficar bem claro que na sua atividade é essencial a biossegurança, colocando em prática normas básicas de higiene rigorosa, adotando as Precauçőes Universais para contato com sangue e líquidos corporais independente da patologia do doente e/ ou potencialmente contaminante do material".

A incidéncia do uso de luvas de $44 \%$ pelos funcionários, apesar de relevante, não se mostra significativa, visto que a utilização não garante a minimização do risco.

\subsubsection{Uso de Óculos e Máscara}

A observação referente ao uso de óculos e máscara nåo mereceu discussão mais aprofundada, pois năo ocorreu nos procedimentos observados nas duas instituiçø̌es.

\subsection{Dados Referentes a Cuidados na Utiliza- ção de Determinados Materiais, Secre- ções e Dejetos Hospitalares}

A realidade vivenciada pelas pesquisadoras em Belo Horizonte é dicotômica em relação ao manuseio de materiais perfurocortantes.

Algumas instituiçőes utilizam materiais de última geração, extremamente precisos e sofisticados com fabricação amparada por pareceres técnicos de profissionais da área da saúde, com o objetivo de proteção do cliente e do profissional que o manipula, garantindo melhores desempenhos técnicos e, conseqüentemente, aumento de produtividade.

Em contrapartida, outras instituiçőes utilizam material perfurocortante com potencial de risco aumentado, considerando-se o aparecimento da AIDS. Esse risco se caracteriza por: utilização de agulhas não rosqueadas, permitindo a soltura espontânea e ferimentos no profissional; nãoutilização de recipientes de descarte adequados conforme recomendaçőes ministeriais; displicência e desatenção no decorrer de preparo, administração e descarte de material perfurocortante pelos profissionais de enfermagem, quer em decorréncia do desconhecimento dos perigos ligados ao material, quer em relação эo seu baixo grau de escolaridade. Aliada a esses fato- res, a falta de treinamento em serviço e as árduas e sucessivas jornadas de trabalho, resultantes em fadiga e ampliando a possibilidade de acidentes hospitalares.

O Ministério da Saúde ${ }^{17}$ afirma que a contaminação de profissionais de saúde envolvidos na assistência a individuos infectados pelo HIV, através de acidentes com agulha ou sangue sobre a pele e na mucosa é ínfima, entretanto reforça que a adoção de medidas preventivas na rotina de atendimento é desejável.

$O$ que se questiona é se existem estatísticas confiáveis quanto a essa ocorrência, que possam merecer a afirmação de que são mínimas, ou se o que existe é uma subnotificação, uma vez que o registro da ocorrência implica em ônus financeiro e compromisso social com o acidentado, o que nem sempre faz parte dos objetivos institucionais.

\subsubsection{Manuseio de Secreções e Excreções}

A situação do manuseio de secreções e dejetos no meio hospitalar é discrepante. Existem referências - Ministério da Saúde ${ }^{21}$, Boletim Controle de Infecção ${ }^{5}, \mathrm{CClH} / \mathrm{HC}^{8}$ - quanto ao destino adequado de lixo e materiais perfurocortantes dentro dos padrőes aceitáveis para um ambiente seguro, em nível hospitalar.

Entretanto, os riscos tendem a ser maiores para pacientes e trabalhadores, quando estes minimizam os princípios de assepsia e as recomendaçס̋es dos órgãos governamentais quanto a precauçőes universais.

$\mathrm{Na}$ instituição $\mathrm{A}, 75 \%$ dos procedimentos possibilitaram risco e $25 \%$ não possibilitaram.

$\mathrm{Na}$ instituição $\mathrm{B}, 87,5 \%$ dos procedimentos possibilitaram risco e $12,5 \%$ não possibilitaram.

Convém ressaltar a afirmativa do Ministério da Saúde ${ }^{21}$ que adverte que o profissional de saúde deve considerar todo sangue e secreção, excluindo lágrima, suor e saliva, como potencialmente infectantes.

\subsubsection{Manuseio de Material Perfurocortante}

Analisando o manuseio de material perfurocortante quanto à possibilidade de risco, consta- 
tou-se, na instituição A, que $29 \%$ dos procedimentos observados possibilitaram risco ao funcionário e $71 \%$ não possibilitaram risco. $\mathrm{Na}$ instituiçăo B, $57 \%$ dos procedimentos observados possibilitaram risco e $43 \%$ não o possibilitaram.

É importante realçar que os $\mathbf{5 7 \%}$ (referentes à instituição B) possibilitaram risco, devido à reencapagem de agulhas, fato que se contrapōe às informaçőes veiculadas nos folhetos sobre a utilizaçăo das medidas de biossegurança existentes na instituiçăo proibindo a reencapagem de agulhas.

Em dados publicados no Boletim Controle de Infeç̧ão, editado pela Becton Dickinson 5 , "a cada 30 segundos - cerca de um milhăo de vezes por ano - um médico, enfermeiro ou qualquer outro profissional de saúde norte-americano fura-se acidentalmente com agulha potencialmente contaminada, sujeitando-se, desta forma, aos riscos de contaminação com vírus, como o da AIDS ou da hepatite. Em 1989, mais de 12 mil profissionais de saúde naquele país infectaram-se com hepatite e 250 destes vieram a falecer".

Outro dado de estatística norte-americana registra a ocorrência de 800 mil casos anuais de acidentes com materiais perfurocortantes, sendo em 1990 contaminados 18 mil profissionais de saúde com o vírus da hepatite $B$, ocorrendo 300 obitos deste total.

Enfatizando o risco decorrente do manuseio inadequado de perfurocortante, PRAÇA e GRAN$D^{24}$ relataram que vários autores abordaram a possibilidade de maior risco de transmissão do HIV por exposiçăo parenteral nos países do Terceiro Mundo. Tal fato se deve à falta de treinamento de pessoal que administra medicamentos, à precariedade do equipamento disponivel e às práticas inadequadas de esterilizaçăo.

\subsubsection{Manuseio de Roupas e Campos Con- taminados}

$\mathrm{Na}$ instituição $\mathrm{A}$, observou-se a ocorrência de manuseio de roupas e campos usados em $25 \%$ dos procedimentos; entretanto, os principios científicos foram assegurados no manuseio de todos eles.
Segundo o Ministério da Saúde, no Manual de Controle de Infecção Hospitalar ${ }^{8}$, as trocas de roupa deverăo ser feitas com a menor agitaçăo possivel, a fim de evitar a dispersăo de microorganismos no ar, especialmente as de pacientes submetidos a isolamento respiratório, as de doenças com lesర̃es cutâneas suturadas, ou com infecçőes intestinais. O recolhimento deverá ser feito em sacos impermeáveis, identificando-se os mesmos contendo as roupas dos pacientes acima citados, devendo ser encaminhados à lavanderia, fechados. A manipulação da roupa usada deve ser reduzida ao mínimo e seguida sempre de anti-sepsia das măos.

$\mathrm{Na}$ instituiçăo B, o manuseio ocorreu em $30 \%$ dos procedimentos e constatou-se que apenas um funcionário desprezou a roupa em carrinho próprio, imediatamente após o uso. Os demais, após a utilizaçăo, continuavam executando os procedimentos nas diversas enfermarias, permanecendo com o material contaminado em saco plástico ou envolvido no próprio campo no carrinho de curativo que utilizava para a execução de outros procedimentos. Tal prática foi justificada por uma funcionária, alegando falta de tempo para o deslocamento até o local de descarte da roupa e do material, bem como economia de saco plástico para acondicionamento.

A utilização de sacos plásticos é necessária ao acondicionamento de roupas, principalmente quando a planta física não atende a requisitos mínimos de assepsia para o desempenho dos profissionais.

A exposição a riscos constantes, pelo pessoal de enfermagem não qualificado a agentes patogénicos veiculados pela roupa, é "corriqueira ". Essa situação é preocupante em face do surgimento advento de novas cepas de bactérias e vírus altamente patogénicos e multirresistentes.

\section{CONCLUSÃO}

O presente estudo permitiu observar a existência e a utilização das medidas de biossegurança pelo pessoal de enfermagem, em duas instituições de saúde de Belo Horizonte. 
Pode-se afirmar que os profissionais de enfermagem, nas diversas categorias, conhecem as medidas de biossegurança, entretanto não as empregam adequadamente, embora ocorra priorização do uso de material descartável nas duas instituiçőes observadas.

A observância às normas governamentais não é total, visto que:

- a lavagem das mãos apresentou dados preocupantes, pois na instituição $A 37,5 \%$ dos funcionários não lavaram as mãos antes da execução dos procedimentos e na instituição B $80 \%$ não o fizeram.

Após a execução dos procedimentos, $25 \%$ dos funcionários da instituiçăo $A$ não lavaram as mãos e 37,5\% utilizaram apenas álcool, procedimento que, por si só, não representa medida para garantir uma devida assepsia.

$\mathrm{Na}$ instituição B $80 \%$ dos funcionários năo lavaram as mãos após a execuçăo dos procedimentos;

- O uso de luvas foi omitido em $75 \%$ dos procedimentos observados, e nem mesmo esse uso pelos funcionários em $25 \%$ dos procedimentos impediu a autocontaminaçăo durante a execuçăo.

Esses dados deveriam atingir um percentual de utilizaçăo de $100 \%$, em face da dissemina- ção da AIDS e de outras doenças infecto-contagiosas. Há risco de transmiti-las ou adquiri-las durante a execução dos procedimentos de enfermagem, mesmo utilizando material descartável.

O trabalho permitiu detectar, também, a existência de riscos decorrentes do manuseio inadequado de secreçס̋es, excreçర̃es, roupas e campos contaminados, bem como da manipulação de material perfurocortante, lixo e dejetos resultantes da execução dos procedimentos.

A situação observada é preocupante e merece ser olhada com rigor pelas chefias de enfermagem dos estabelecimentos de saúde. Tal conduta objetiva um maior controle da veiculação do HIV e busca de condiçőes seguras de trabalho para os profissionais de enfermagem.

Essa área necessita de investigação mais profunda, visto serem percebidas condutas de risco na visão das pesquisadoras, que alertam os profissionais de enfermagem para os fatores de risco e necessidade da utilização das medidas preconizadas, no seu processo de trabaIho, minimizando o risco de contrair doenças, incluindo a AIDS, em decorrência do exercício profissional.

\begin{abstract}
The work is a descriptive exploratory study aiming to verify the existence of rules and the use of biosafety means by nursing staff, for the prevention of HIV transmition, during the procedures in medical-surgical clinics in two hospitals in the city of Belo Horizonte. Through the observation of these procedures, it has been found the existence of risks derived from inappropriated handling of contaminated secretion, excretion, cloths and sheets as well as perforative and cutting material waste and garbage. It can be said that the nursing professionals in their various categories, know the biosafety means, but don't use them appropriately. The observed situation is preoccupying and deserves to be looked upon with strictness by the supervisor nurses in Health Institutions, aiming a better control of the veiculation of HIV, and seeking safety work conditions for nursing staff. This area needs a deeper investigation once it has been perceived dangerous conducts, in the eyes of the researchers.
\end{abstract}

KEYWORDS: HIV/Biosafety - Occupational Risk - HIVINursing Practice 


\section{REFERÊNCIAS BIBLIOGRÁFICAS}

01. ALMEIDA, M. C. P. Estudo do saber de enfermagem e sua dimensão prática. RJ. 1984. (Tese de Doutorado) E. N.S.P. Fundação Oswaldo Cruz.

02. ALMEIDA, M. C. P. et al. Contribuição ao estudo da prática da enfermagem - Brasil. Ribeirão Preto: Escola de Enfermagem de Ribeirão Pre-to. $1981.58 \mathrm{p}$.

03. ANGERAMI, E. L. S. e colaboradora. De como o enfermeiro está inserido no seu espaço. Rev. Bras. Enf. RS. 36 : 123 - 129, 1983.

04. BERGAMO, M et al. Procedimentos técnicos básicos na prevenção da Aids num centro cirúrgico de grande porte. Revista Brasileira de Enfermagem. 1988.Abril/ Maio/ Junho. p155-160.

05. Boletim Controle de Infecção.1991. Becton dickinson. Ano 4. n. 15, abril/ maio/ junho.

06. Boletim Controle de Infecção.1991. Becton dickinson. Ano 4. n.16, julho/ agosto/ setembro.

07. Boletim Controle de Infeç̧ão. 1992. Becton dickinson. Ano 5. n. 17, janeiro/ fevereiro/março.

08. COMISSÃO DE CONTROLE DE INFECÇÃO HOSPITALAR (CCIH) DO HOSPITAL DAS CLÍNICAS DA UFMG.Manual de Infecção Hospitalar Prevenção e Controle.Rio de Janeiro : MEDICI, 1993.297p.

09. CONSELHO FEDERAL DE ENFERMAGEM. O exercicio da enfermagem nas instituições de saúde do Brasil - 1982/1983: força do trabalho em enfermagem. Rio de Janeiro, Conselho Federal de Enfermagem/Associação Brasileira de Enfermagem, 1985. v1. p.35-42.

10. CONSELHO FEDERAL DE MEDICINA (BRASIL). Código de Ética Médica. Resolução CFM $n$. 1246/88 - RJ. 1988. 63p.

11. DESSUNTI, M .E . Percepção de Discentes e Equipe de Enfermagem em Relação ao Paciente com suspeita ou diagnóstico confirmado de AIDS. 1989. Revista Gaúcha de Enfermagem. Porto Alegre, 10 (1): 45-51, Jan.

12. FERNANDES, J. D. A enfermagem no ontem, no hoje e no amanhã. Rev. Bras. Enf. Brasilia, 38 (1) : 43 - 48, jan / mar. 1985.

13. JORNAL DOS CONSELHOS. Transmissão por HIV. Belo Horizonte/MG. ano 1 n. 0 - 1988.
14. KLEIN, S.R. Occupation transmission of HN. cap 2. p12-13. Texto datilografado sem data. EEUFMG.

15. MARIN. F. H et al. AIDS e a enfermagem obstétrica. 1991. São Paulo. 61p.

16. MENDES, D. C. Assistência de enfermagem e administração de serviços de enfermagem: a ambiguidade funcional do enfermeiro. Rev. Bras. Enf. Brasilia, 38 (3,4): 257 - 265, jul / dez. 1985.

17. MINISTÉRIO DA SAÚDE. AIDS. Recomendações Técnicas e Aspectos Éticos. 1988. 24p.

18. MINISTÉRIO DA SAÚDE. SIDA / AIDS. Recomendações para hospistais, ambulatórios médicos, odontológicos e laboratórios. In: Normas e manuais técnicos, Brasilia: 1988.

19. MINISTÉRIO DA SAÚDE. Normas de organização e funcionamento dos centros de orientação e apoio sorológico. 1993. Brasília.

20. MINISTÉRIO DA SAÚDE. Secretaria Nacional de Programas Especiais de Saúde. Divisão Nacional de Doenças Sexualmente Transmissiveis / AIDS. Organização Panamericana de Saúde - OPS. Manual de aconselhamento / AIDS. Brasilia, 1989. $31 \mathrm{p}$.

21. MINISTÉRIO DA SAÚDE. Normas técnicas para controle da AIDS e outras infecções virais na prática odontológica. $2^{\mathrm{a}}$ ed. Brasília, 1989, 22p.

22. OGUISSO, T. A responsabilidade legal do enfermerio. Rev. Bras. de Enfermagem, Brasilia, 38 (2):185 - 189, abril / junho. 1985.

23. OGUISSO, T. e SCHMIDT, M. J. A enfermagem e a insalubridade. Revista Paulista de Enfermagem, São Paulo, 4 (2) : 43 - 48, abril / junho, 1984.

24. PRAÇA e GRANDI. A Enfermeira Obstétrica e a prevenção no Risco Ocupacional de Contaminação pelo Vírus HIV em Centro Obstétrico. Rev. Brasileira de Enfermagem, 1989. 42. p 101 a 105, jan/dez.

25. PRATT, Robert J. AIDS uma estratégia para assistência de enfermagem. Tradução de Adelia Maya Chida São Paulo, 1986, 136 p.

26. SILVA, N. F. A prática da enfermagem na Bahia. Contribuição ao estudo do trabalho dos profissionais de enfermagem de nivel superior. Salvador: Gráfica Central, 1987. 